\title{
Empresa Júnior: espaço criativo e empreendedor de ensino-aprendizagem na Enfermagem
}

\author{
Recebido em: 20/12/2012 \\ Aprovado em: 25/11/2014
}

Carla Aparecida Spagnof' Joana Melillo Bastos²

Resumo: A Empresa Júnior (EJ) é uma das formas de ensino-aprendizagem na enfermagem, a fim de preparar indivíduos para aprender a aprender e conquistar um diferencial na sua carreira profissional. É uma estratégia de ensino criativa que possibilita a atualização e contribui na formação de profissionais empreendedores. Objetivou-se apresentar a EJ como um espaço criativo e empreendedor para o processo de ensino-aprendizagem dos alunos da Enfermagem e da área da saúde. A Arterial, EJ da Escola de Enfermagem da Universidade Federal de Minas Gerais (EE-UFMG), foi criada em 2008, com o objetivo de capacitar o futuro enfermeiro para desenvolver habilidades gerenciais e de liderança. Vários projetos foram realizados: realização de oficinas, eventos científicos e acadêmicos; ações de responsabilidade social; além de fixação de parcerias. A experiência do ensino do empreendedorismo constitui-se em um importante espaço de formação acadêmica, preparando os estudantes para serem profissionais de excelência no mercado de trabalho. Descritores: Gestão em Saúde, Enfermagem, Educação em Saúde.

Junior Company: a creative and entrepreneurial space for teaching-learning in Nursing/Health

Abstract: The aim of this study was to analyze the study and research groups, of the nursing area, registered in the Directory of Research Groups of the National Council to Development Scientific and Technological, which have a line of research with emphasis on the elderly. This is a documentary research, held between August and October 2011, the analysis occurred by descriptive statistics, by frequency calculations. Were identified 51 groups, with highest concentration in the northeast, southeast and south. Glimpses the need of studies directed the elderly and the importance of the nurses participation in the study and research groups, which can contribute to strengthening and search for new knowledge in the subject investigated.

Descriptors: Health Management, Nursing, health Education.

\section{Empresa Júnior: espacio creativo y emprendedor de enseñanza-aprendizaje en Enfermería/Salud}

Resumen: El objectivo fue analizar los grupos de estúdio e investigación del área de enfermería, registrados en el directorio de Grupos de Investigación del Consejo Nacional de Desarrollo Científico y Tecnológico, que tienen uma línea de investigación con énfasis en los ancianos. Investigación documental realizada entre agosto y octubre de 2011, cuyo análisis fue mediante estadística descriptiva por medio de cálculos de frecuencia. Se identificaron 51 grupos con la mayor concentración en El Nordeste, Sudeste y Sur. Se vislumbra de la necesidad de estúdios a los ancianos y la importancia de la participación de las enfermeras en los grupos de estudio e investigación, que puede contribuir al fortalecimiento y la búsqueda de nuevos conocimientos en el tema investigado.

Descriptores: Gestión en Salud, Enfermería, Educaión em Salud.

\section{INTRODUÇÃO}

$\mathrm{O}$ mpreendedorismo é um termo antigo que surge por volta do século XV na França, mas é a partir do século XXI que pesquisadores, empresários e governantes começam a se interessar por esse fenômeno ${ }^{(1)}$, devido as constantes e complexas transformações nos aspectos sociais e econômicos do mundo contemporâneo.

As organizações, cada vez mais, têm introduzido novos modelos de gestão para se adequarem às demandas emergentes e atuais, buscando flexibilizar suas estruturas, descentralizar as decisões, agilizar os processos e intensificar a comunicação, a fim de obterem produtos e serviços de qualidade. Esse cenário aponta uma tendência de se deslocar o foco da gestão do controle para uma gestão de desenvolvimento pessoal, dando maior relevância às pessoas, para se buscar o sucesso das organizações.

Nesse atual contexto de incertezas e desafios, o desenvolvimento e a sobrevivência das organizações "dependem, em grande parte, da formação e capacitação de seus atores, voltadas não só para conhecimentos e habilidades de natureza técnica e gerencial, mas, também, para a criatividade e auto-realização, o que expressa aspectos fundamentais do empreendedorismo"(1:5).

O empreendedorismo é um tema universal e que deve ser oferecido para todos os alunos desde a educação básica, visto que seu fundamento é a cidadania e busca a construção do bem-estar da coletividade, do espírito comunitário e da cooperação. Além disso, o empreendedorismo é uma das melhores estratégias encontradas nos dias de hoje para se reduzir o desemprego ${ }^{(2)}$

O termo empreendedor, do francês entrepreneur, caracteriza aquele que assume riscos e começa algo novo. Eempreendedorismo é uma tradução livre da palavra entrepreneurship que contém as ideias de iniciativa e inovação. É uma palavra que sugere um modo de ser, uma concepção de mundo, uma forma de se relacionar. "O empreendedor é um insatisfeito que transforma seu inconformismo em descobertas e propostas positivas para si mesmo e para os outros", está em qualquer área de atuação e, portanto, não é considerado somente aquela pessoa que pretende abrir uma empresa ${ }^{(2: 26)}$.

A pessoa empreendedora apresenta algumas habilidades e características de comportamento como a busca de informações, oportunidades e iniciativa; disposição para correr riscos calculados; gerenciamento; planejamento; estabelecimento de metas e de rede de contatos; exigência de qualidade e eficiência; comprometimento; persuasão; independência; confiança e auto confiança; persistência; intuição; esperança; liderança e inovação.

Na área da saúde a pessoa do empreendedor ainda é nova, mas, vem ganhando destaque devido à necessidade de se gerar novos postos de trabalho, em função dos rápidos avanços tecnológicos ${ }^{(3)}$.

Esse caráter incipiente do empreendedorismo na saúde pode ser exemplificado por um estudo realizado com quarenta e um (41) estudantes de enfermagem da rede privada da cidade de São Paulo-SP, o qual concluiu que, $80 \%$ dos pesquisados apresentaram fraquíssima ou nenhuma tendência empreendedora, ressaltando

1Enfermeira. Doutora em Saúde Coletiva. Profa. Adjunto da Escola de Enfermagem da Universidade Federal de Minas Gerais. Email: spagnol@ufmg.br

${ }^{2}$ Enfermeira. Graduada pela Escola de Enfermagem UFMG. 
que a dimensão criativa foi a que menos apareceu (36\%) nas respostas obtidas ${ }^{(3)}$. Nessa investigação os autores concluíram que os alunos de enfermagem têm poucas características empreendedoras, o que mostra a necessidade de se investir cada vez mais na formação desses futuros profissionais, tendo em vista que o mercado de trabalho está cada vez mais exigente e competitivo.

Na lógica do empreendedorismo social o processo de formação precisa incitar nos alunos, principalmente os da enfermagem, "uma nova concepção de mundo, de sociedade e de ser humano, pela ampliação do conceito de cuidado/saúde e a exploração de novos espaços de atuação profissional ${ }^{(4 ; 5: 247)}$.

Nessa perspectiva, a criação de uma Empresa Júnior (EJ) pode ser um primeiro passo, para professores e alunos investirem em outras formas de ensino-aprendizagem na enfermagem, a fim de preparar indivíduos para aprender a aprender, estimulando os alunos a saírem do lugar comum e conquistar algo a mais na sua futura carreira profissional. Essa é uma estratégia de ensino criativa que possibilita a atualização constante e contribui na formação de profissionais empreendedores, que atendam à realidade brasileira do mercado de trabalho.

A Empresa Júnior (EJ) é uma associação civil sem fins econômicos, constituída exclusivamente por alunos de graduação de Instituições de Ensino Superior (IES), que prestam serviços de consultoria, assessoria e desenvolvem projetos para empresas, entidades e sociedade em geral, sob a orientação de professores ou profissionais do mercado(5).

A missão de uma EJ é criar uma cultura dentro das IES brasileiras, visando o desenvolvimento de empreendedores e lideranças, com responsabilidade social. Valores como ética, cooperação, empreendedorismo, profissionalismo, inovação e determinação devem ser priorizados para garantir o sucesso dessas empresas $^{(6)}$.

A primeira Empresa Júnior surgiu em Paris, França, na ESSEC - Ecole Supérieure des Sciences Économiques et Commerciales, em 1967. A sua criação foi motivada a partir do diagnóstico da necessidade dos acadêmicos em aplicar na prática os conhecimentos teóricos vistos em sala de aula, percebida através de pesquisas e estudos de mercado. O seu objetivo era oferecer aos alunos de cursos superiores uma opção de aperfeiçoamento da formação profissional. Essa iniciativa se expandiu rapidamente e, em 1968, foi criada a Confederação das Empresas Juniores da França. O movimento ganhou envergadura nacional naquele país em 1982, eclodindo nas grandes escolas francesas e levando ao surgimento de setenta (70) associações no modelo de Empresa Júnior ${ }^{(6)}$.

Em 1986, quando já existiam mais de cem (100) Empresas Juniores francesas, o conceito começou a difundir-se pelo restante da Europa, onde encontrou novos formatos e ocasionou, em 1990, a criação da Confederação Européia de Empresas Juniores, a JADE (Junior Association for Development in Europe). Hoje existem Empresas Juniores espalhadas por todo mundo.

No Brasil, a idéia foi introduzida pela Câmara de Comércio França-Brasil (CCFB), que em 1987, publicou um anúncio num jornal convocando jovens interessados em implantar uma Empresa Júnior. A partir de 1988, surgiram as primeiras Empresas Juniores, na Fundação Getúlio Vargas e na Universidade de São Paulo ${ }^{(7)}$. Em 2003, foi criada a Confederação Brasileira de Empresas Juniores, conhecida como "Brasil Júnior", que tem como objetivos organizar, representar e auxiliar no trabalho das onze (11) federações estaduais já filiadas.

Atualmente, na Europa, o Movimento Empesa Junior (MEJ) existe em treze (13) países, reunindo cerca de trezentas (300) empresas e vinte mil (20.000) empresários juniores. No Brasil, existem mais de seiscentas (600) empresas e vinte mil (20.000) empresários juniores, sendo o país que hoje apresenta o maior número de empresas dessa natureza. Isso evidencia que o MEJ brasileiro se construiu de forma bastante ordenada e com uma estrutura adaptada à nossa realidade(6).

A Empresa Júnior busca disponibilizar para a sociedade produtos e serviços de excelência, gerando conhecimento e reconhecimento social da competência dos seus integrantes e da Instituição de Ensino a que pertence. A qualidade dos projetos e dos estudos a serem realizados é garantida pela orientação dos professores das IES, onde estas empresas estão estabelecidas, ou ainda pelo auxílio de profissionais da área. Portanto, seu principal objetivo é o aprendizado e desenvolvimento do aluno e não resultados financeiros.

Outro aspecto a ser ressaltado é a produção do conhecimento no meio acadêmico, no qual os professores e alunos têm a oportunidade de repensar o processo do ensino-aprendizagem, adequando-o ao mercado de trabalho, tendo em vista às necessidades de formação do futuro profissional.

Assim sendo, objetivou-se apresentar a Empresa Júnior como um espaço criativo e empreendedor para o processo de ensinoaprendizagem dos alunos da Enfermagem.

\section{Empresa Júnior: espaço criativo e empreendedor de ensino- aprendizagem na formação do enfermeiro e outros profissionais de saúde}

A finalidade da Empresa Junior de Enfermagem é promover ações de intercâmbio com a sociedade, que resultem na criação, desenvolvimento e consolidação de uma cultura empreendedora e do estímulo à geração de novos empreendimentos na área da saúde que respeitem o cliente e suas necessidades.

Os alunos de graduação, sob a supervisão de professores, podem aplicar seus conhecimentos adquiridos, desenvolvendo projetos para atuarem em organizações públicas e privadas como escolas, asilos, creches, hospitais, enfim na comunidade de modo geral, contribuindo para a prestação de uma assistência segura e livre de riscos à população, para o aperfeiçoamento da formação profissional e o fortalecimento da educação permanente dos profissionais da saúde, especificamente os da enfermagem.

Em 2006, duas alunas do $5^{\circ}$ período do Curso de Enfermagem da Universidade Federal de Minas Gerais, apresentaram à direção da escola o projeto de criação da Arterial UFMG-Consultoria e Assessoria Júnior em Enfermagem. Essa ideia foi motivada por diversas razões, dentre elas a necessidade de capacitar o futuro enfermeiro para desenvolver habilidades gerenciais e de liderança, a fim de administrar equipes e organizações, mais especificamente, às do setor saúde.

Com espírito empreendedor as referidas alunas partiram do princípio que a criação de uma EJ poderia permitir aos alunos adquirirem, precocemente, capacidade e autonomia para administrarem organizações na área da saúde. Assim, mais do que simplesmente construir a proposta de uma Empresa Júnior na Enfermagem, esse projeto consistiu em gerar uma estratégia inovadora na formação do enfermeiro.

A Arterial, Empresa Júnior da Escola de Enfermagem da Universidade Federal de Minas Gerais, foi criada no dia 18 de março de 2008, com a finalidade de proporcionar aos estudantes oportunidade para a aplicação prática de seus conhecimentos técnicos e científicos abordados em sala de aula, desenvolvendo espírito empreendedor e oferecendo à comunidade produtos/ 
serviços de qualidade, por meio de projetos realizados sob a orientação de professores ou profissionais especializados, facilitando a inserção desses futuros profissionais no mercado de trabalho.

A criação da Arterial envolveu três processos, que ocorreram paralelamente: o humano, o burocrático e o físico.

O processo humano envolveu basicamente a formação de um grupo inicial de alunos para a abertura da Empresa Júnior e sua direção; a seleção de membros para o desenvolvimento dos projetos; a conquista do apoio da Diretoria da Instituição de Ensino Superior; o contato com professores e/ou profissionais para a orientação das atividades; o estudo de formas de prospecção de clientes.

Em relação ao processo burocrático, a elaboração do Estatuto foi a peça fundamental para a estruturação da Arterial e sua inscrição no Cadastro Nacional de Pessoas Jurídicas- CNPJ. Além disso, outros documentos foram elaborados: Estatuto Social, o Regimento Interno e Guias Operacionais/manuais, que definiram o funcionamento da empresa e como ela deveria ser regulamenta.

Outro aspecto relevante foi o espaço físico específico para a empresa, cedido pela diretoria da escola, com toda infra-estrutura necessária para atender os clientes e desenvolver os trabalhos.

A estrutura organizacional da Arterial foi composta da seguinte forma: presidência, vice-presidência, diretoria administrativofinanceira, diretoria de marketing e relações públicas, diretoria de projetos, diretoria de recursos humanos, assessores do presidente e da diretoria de marketing. Foi realizada uma eleição para a escolha do presidente e os demais membros para serem admitidos que passaram por um processo seletivo e o Programa Trainee.

Com a implantação dos Cursos de Nutrição e Gestão de Serviços de Saúde na Escola de Enfermagem da Universidade Federal de Minas Gerais (EEUFMG) e buscando um trabalho multiprofissional, com vistas à interdisciplinaridade, a direção da Arterial em 2009, até então composta exclusivamente por alunos de enfermagem, abriu processo seletivo para admitir os estudantes matriculados nos três cursos, agora, oferecidos pela escola. A partir de abril 2010, diante desse novo contexto, a Empresa Junior passou a chamar-se Arterial UFMG Jr. Consultoria e Assessoria em Saúde.

A Arterial UFMG Jr. tem como missão proporcionar aos acadêmicos da Escola de Enfermagem da UFMG a oportunidade de desenvolver e fomentar o empreendedorismo visando promoção da saúde e desenvolvimento social. E tem como visão ser uma das melhores oportunidades de complementação acadêmica da EEUFMG, conquistar a gestão por excelência e oferecer um dos melhores serviços em promoção da saúde na Região Metropolitana de Belo Horizonte até 2015.

Vários projetos já foram realizados pelos membros da Arterial UFMG Jr., desde a realização de eventos científicos e acadêmicos sobre Empreendedorismo e saúde, acreditação hospitalar, inserção dos profissionais de saúde no mercado de trabalho, palestra sobre o trabalho dos médicos sem fronteiras. Realizaram, ainda, ações de responsabilidade social como Confraternização de Natal em uma creche de Belo Horizonte e fixaram parceria com hospital filantrópico para colaborar nos treinamentos e capacitações da equipe de enfermagem. $\mathrm{O}$ coffee break é um dos produtos oferecidos a baixo custo no mercado e o cardápio é elaborado de forma balanceada pelos alunos da nutrição.

Atualmente, os empresários juniores da Escola de Enfermagem estão investindo na elaboração de projetos de assessoria e consultoria sobre infecção hospitalar, para serem oferecidos à diversos serviços de saúde, além de Oficinas sobre sexualidade para capacitar professores e alunos de escolas públicas e privadas do ensino fundamental e médio.

\section{CONSIDERAÇÕES FINAIS}

A experiência dos alunos da Escola de Enfermagem UFMG é recente no que diz respeito ao tema empreendedorismo e a constituição de uma Empresa Junior como um espaço de ensino-aprendizagem, diferentemente, de outras áreas como a administração de empresas, a engenharia, a ciência da computação e outras que iniciaram esse processo há mais tempo. No entanto, pode-se dizer que são vários os benefícios que esses acadêmicos poderão obter ao longo da sua formação profissional.

Em relação, especificamente, à formação do enfermeiro nesse atual mercado de trabalho exigente e competitivo, os alunos de enfermagem que atuam na Arterial UFMG Jr. poderão ter as seguintes vantagens em relação aos demais estudantes: ter visibilidade no mercado ainda como acadêmico; a possibilidade de ter contato com profissionais de ponta no mercado, podendo iniciar suas redes de contato; desenvolver capacidade de liderança e trabalho em equipe; adquirir auto-confiança e controle; ter oportunidade de trabalhar precocemente na sua área de atuação; utilizar instrumentos de gerência; exercitar a gestão do tempo; ter persistência, coragem e ousadia.

Portanto, a experiência da Empresa Júnior e do ensino do empreendedorismo quando bem elaborada e organizada, pode constituir-se em um importante e criativo espaço de formação acadêmica, preparando os estudantes para serem profissionais de excelência no mercado de trabalho.

Para finalizar sugere-se a realização de estudos sobre o empreendedorismo na saúde e, especificamente, na enfermagem devido a escassez de literatura sobre o tema, pois, são os resultados de pesquisas, relatos de experiência e artigos de atualização, que contribuem para o crescimento científico e as inovações na profissão.

\section{Referências}

1. Souza ECL, Guimarães TA, organizadores. Empreendedorismo além do plano de negócio. São Paulo: Atlas; 2005.

2. Dolabela F. O segredo de Luísa. São Paulo: Cultura; 2006.

3. Roncon PF, Munhoz S. [Estudantes de enfermagem têm perfil empreendedor?] Rev Bras Enferm. 2009; 62(5): 695-700.

4. Backes DS, Erdmann AL, Buscher A. [O cuidado de

enfermagem como prática empreendedora: oportunidades e

possibilidades.] Acta Paul Enferm. 2010; 23(3): 341-7.

5. Backes DS, Erdmann AL. [Formação do enfermeiro pelo olhar do empreendedorismo social.] Rev Gaúcha Enferm. 2009; 30(2): 242-8. Português.

6. Brasil Júnior. Confederação Brasileira de Empresas Juniores. Conceito Nacional de Empresa Júnior. Salvador (BA): Brasil Júnior; 2006. Disponível em: <http://uaua.ufba.br/brasiljr/>.

7. Franco AP, Feitosa MGG. Da sala de aula ao mundo empresarial: compreendendo a aprendizagem dos consultores juniores e suas relações com o sistema-cliente. In: 30 Encontro ANPAD; 2006 set 23-27; Salvador. Anais. Salvador: ANPAD; 2006. 